\title{
The influence of hydroxyaryls of various genesis on the growth and development of winter wheat (Triticum aestivum L.)
}

\author{
Svetlana Konoshina ${ }^{1, *}$,Elena Prudnikova $^{1}$, Alexey Gorkov ${ }^{2}$, Yulia Mikhaylova ${ }^{1}$, and \\ Oksana Koneeva ${ }^{1}$ \\ ${ }^{1}$ FSBEE HE OrelSAU, 302019 Orel, Russian Federation \\ ${ }^{2}$ FSBSI FSC GLC, 302502 Orel district, Orel region, Russian Federation
}

\begin{abstract}
The analysis of the available bibliographic data on the influence of hydroxyaryl compounds on the growth and development of grain legume crops grown on different soils is carried out. The content of the hydroxyaryl compounds in various types of soils has been studied. Their maximum amount in the chernozem soils has been defined. A decrease in the amount of the hydroxyaryl compounds with an increase in the depth of sampling was revealed. The quantitative content of the polyphenol oxidase enzyme has been established in the seeds of winter wheat variety Grom. The effect of hydroxyaryl compounds of exogenous plant origin on the development of winter wheat seeds in various soil conditions has been analyzed. The soils rich in hydroxyaryls are more favorable for seed growing and development. The options with the use of exogenous hydroxyaryl compounds of plant origin and chernozem had the maximum stimulating effect, while sand samples had the minimum one.
\end{abstract}

\section{Introduction}

Nowadays, biologization of technological production processes, that is, effect of biologically active substances on the agrocenosis, in order to reduce the pesticide effect and increase the productivity of the agricultural crops is a relevant direction of the agricultural development. The greatest attention is paid to the study of the interaction between plants and soil. Physiologically active substances of various chemical composition and origin are widely represented both in the soil as in the plants. In addition to the mineral, organic and organo-mineral components of the soil, the products of plant metabolism, accumulated after the dieback, occupy a special place. Due to it, the soil has a certain physiological and biochemical activity [1], which has a phyto-inhibiting or phyto-stimulating effect on plants.

At present, one of the most important fields of the research is a study of soil phytotoxicity, which is a result of the phenolic substances accumulation in it [2]; they were found at various levels of biological systems. These substances are able to regulate various processes of plant life, including metabolic processes and cell division regulation. [3]. The content of the hydroxyaryl compounds in plants can change under the influence of external

${ }^{*}$ Corresponding author: graduate_orelsau@mail.ru 
factors, soil factor [4] for example. The hydroxyaryl compounds are accumulated in various parts of plants. When harvesting agricultural plants, hydroxyaryl compounds are also removed from the agrophytocenosis, for example, hydroxyaryl compounds contained in the buckwheat husks. The non-commercial part of the crop, including the husks, can be used as a source of hydroxyaryl compounds for various purposes [5].

Based on the mentioned above, the aim of the work was: to determine the content of the hydroxyaryl compounds in different types of soil and in winter wheat seeds; to reveal the joint effect of soil polyphenols, including those formed as a result of vital activity, on the ontogenesis of higher plants, as well as the possibility to use them as a source of energy for germination of seeds of Triticum aestivum L.

\section{Materials and methods}

The objects of the study were samples of podzolized chernozem and gray forest soil, seeds of the Triticum aestivum L., variety Grom and buckwheat husks (Fagopýrumesculéntum) as a source of polyphenolic compounds. On the basis of the colorimetric analysis, using the Folin-Denis reagent, the total content of hydroxyaryls was determined. The reference concentration of allelochemicals was defined using the bioassay test [6]. The polyphenol oxidase activity was determined while measuring the optical density of the products of the oxidation of prirocatechol in the presence of diethylparaphenylenediamine [7]. The wheat seeds were sown into the samples of various soil types and treated with a solution of plant hydroxyaryls to detect the effect of the absorption and retention capacity of the soil complex. Buckwheat seed husks were used to obtain the phenolic compounds. Heat-treated and washed river sand was used for the control. The hydroxyaryl compounds were introduced to water winter wheat at a concentration of $0.01 \mathrm{ml}$ per $100 \mathrm{ml}$ of water. The experimental options were the following: sand with the addition of the phenolic extract; sand with clean water irrigation; gray forest soils, with the addition of the phenolic extract; gray forest soils with clear water irrigation; chernozem with the addition of the phenolic extract; chernozem with clean water irrigation. The biometric indicators of Triticum aestivum L. were recorded in 10 days after sowing. The reliability of the research results was assessed based on the analysis of variance.

\section{Results and discussion}

The analysis of the greenhouse experiment was carried out according to the following indicators: the content of the hydroxyaryl compounds in the soil, the activity of polyphenol oxidase in the seeds of winter wheat, their germination, the length and weight of winter wheat seedlings.

The polyphenol oxidase enzyme is a widespread enzyme in nature and belongs to the class of oxidoreductases; it participates in the oxidation of o-diphenols, as well as monoand polyhydroxyaryls with the formation of the corresponding quinones. The content of its own hydroxyaryl compounds in the seeds of wheat variety Grom changed insignificantly during the years of the research (50.6 - 50.9 mg/ $100 \mathrm{~g}$ of the wet weight). Polyphenol oxidase activity ranged from 0.96 to 1477 conventional units / g of the wet weight. Different enzyme activity is associated with different weather conditions preceding the wheat seed harvesting. Thus, the moisture supply of the agricultural crops in 2018 was lower than in 2019 relatively to the average values for 1999-2017.

Buckwheat husks were used as a source of exogenous phenols. The total content of the hydroxyaryl compounds in buckwheat husk was $0.1 \mathrm{~g}$ in $10 \mathrm{~g}$ of husks. 
The content of hydroxyaryls differs depending on the soil type. A large amount of the hydroxyaryl compounds was determined in the samples of gray forest soils, a smaller amount was observed in the samples with the chernozem, since each type of soil has a different genesis. The maximum amount of the hydroxyaryl compounds was found in the top soil, with an increase in the depth of soil sampling, the content of the hydroxyaryls in the gray forest soils changes insignificantly and amounts to $23 \mu \mathrm{g} / 100 \mathrm{~g}$ of the dry soil, in the chernozem soils this trend is more obvious (the difference between the layer $0-10 \mathrm{~cm}$ and $90-100 \mathrm{~cm}$ is $296 \mu \mathrm{g} / 100 \mathrm{~g}$ of soil). The toxicity of soil samples in relation to the test crops changes with the same regularity: the maximum value in the layer is $90-100 \mathrm{~cm}$, the minimum is in the arable layer of all types of soil. In the conventionally coumarinic units $(\mathrm{CCU})$, the values varied from 10.3 in the arable layer to 41.2 at the maximum sampling depth.

The organic matter of the soil affects not only the formation of soil fertility, but also the processes of plant development, including the growth and development of the test culture. The influence of the hydroxyaryl compounds on the growth and development of higher plants is ambiguous and depends on the species of plants, the stage of their ontogenesis, type and concentration of the hydroxyaryl compounds [9].

To reveal the joint influence of the autologous soil and plant hydroxyaryl compounds of the exogenous origin on the development of seeds, an experiment with the winter wheat variety Grom was carried out. The study revealed the effect of the polyhydroxyaryl compounds on the germinating ability of wheat seeds on soil plates, which differed both depending on the type of soil and on the exogenous effect. The maximum germination capacity was observed in the options with the chernozem, both in the presence of their own hydroxyaryl compounds and when they were introduced from outside, which amounted to $87.3 \%$ and $89.1 \%$, respectively. This effect is probably associated with the ability of buckwheat polyhydroxyaryls to activate growth processes, the peculiarities of the soilabsorbing complex of the chernozem. In the absence of the hydroxyaryl compounds (sand), seed germination was $66.8 \%$, and the introduction of exogenous polyhydroxyaryls stimulated slightly their germination comparing to the control and amounted to $75.7 \%$. The options with the gray forest soils had an intermediate value of seed germination energy, both with the exogenous introduction of polyhydroxyaryls and under the influence of their own polyphenolic compounds. When analyzing the linear sizes of 10-day-old winter wheat seedlings, a stimulating effect was observed in all the options with the participation of the phenolic compounds, which indicates the ability of hydroxyaryls to influence cell division [10].

Among the options subjected to treatment with the phenolic extract, the maximum weight was determined in the plants with the option chernozem with the addition of phenolic extract, the minimum was sand with the addition of the phenolic extract $(0.072 \mathrm{~g} /$ piece and $0.047 \mathrm{~g} /$ piece, respectively), the same dynamics can also be traced when measuring linear parameters $(162.8 \mathrm{~mm} /$ piece and $119.7 \mathrm{~mm} /$ piece). The plants from the options without hydroxyaryl compounds were smaller in size and weight. The largest weight $(0.061 \mathrm{~g})$ was in the plants of the variant chernozem with pure water irrigation, the smallest $(0.034 \mathrm{~g})$ one - sand with pure water irrigation.

Linear parameters of ten-day-old Triticum aestivum L seedlings varied from $157.7 \mathrm{~mm}$ to $110.1 \mathrm{~mm}$, depending on the substrate. When growing Triticum aestivum L. on all experimental samples treated with hydroxyaryl compounds of exogenous origin, positive dynamics of the accumulation of vegetative mass of plants was revealed, ranging from $4 \%$ to $9 \%$. The data obtained indicate the growth-stimulating effect of hydroxyaryl compounds. The coefficient of utilization of phenolic compounds by plants and their involvement in metabolism was analyzed based on the determination of their amount in the soil and in wheat plants of the Grom variety. The analysis of the data presented in Table 1 showed that 
the residual amount of the hydroxyaryl compounds ranged from 1.2 to $0.2 \mathrm{mg} / 100 \mathrm{~g}$, depending on the type of substrate and the type of irrigation. In the "chernozem" soil sample, the accumulation coefficient of the hydroxyaryl compounds was $300 \%$, in the "gray forest soil with the addition of phenolic extract" $200 \%$, which is probably due to the peculiarities of the chemical and physical composition of this soil. According to the data obtained, sand is not capable of accumulating hydroxyaryl compounds. The different content of the hydroxyaryl compounds in seedlings of Triticum aestivum L. indicates the involvement of phenolic compounds of both soil and exogenous origin in the process of germination and further development of plants. Due to the fact that hydroxyaryls are regulators of the transport of auxins - plant hormones, the content of their amount in plants increased during 10 days of growth and development of Triticum aestivum L. plants. The maximum value was found in wheat samples grown on the soil "chernozem with the introduction of phenolic extract" (61.03 mg/ $100 \mathrm{~g}$ wet weight), where the maximum increase in biomass was noted. The minimum value in the sand was $22.4 \mathrm{mg} / 100 \mathrm{~g}$ wet weight). However, it should be noted that due to the low accumulation coefficient of watersoluble hydroxyaryls, the control samples had the maximum dynamics of the accumulation of phenolic compounds compared to soil samples. This pattern emphasizes the importance of long-term fixation of polyhydroskiaril compounds in soil samples in order to increase the duration of the stimulating effect of development.

The dynamics of the changes in the polyphenol oxidase activity has a positive correlation with the content of the hydroxyaryl compounds in the soil and the ground weight of the Triticum aestivum $\mathrm{L}$.

Table 1. The content of the hydroxyaryl compounds in the soil samples and plants after the experiment.

\begin{tabular}{|c|c|c|c|c|}
\hline & Option & $\begin{array}{c}\text { Content of the } \\
\text { hydroxyaryl compounds } \\
\text { in the soil, } \mathrm{mg} / 100 \mathrm{~g} \text { of } \\
\text { soil }\end{array}$ & $\begin{array}{c}\text { Content of the } \\
\text { hydroxyaryl } \\
\text { compounds of the } \\
\text { plant, mg/ } 100 \mathrm{~g} \text { of the } \\
\text { wet weight }\end{array}$ & $\begin{array}{c}\text { Polyphenol } \\
\text { oxidase activity, } \\
\text { ref.un./1 g of the } \\
\text { wet weight }\end{array}$ \\
\hline 1 & $\begin{array}{l}\text { Chernozem with the } \\
\text { introduction of the } \\
\text { phenolic extract }\end{array}$ & $1.2 \pm 0.04$ & $61.0 \pm 1.05$ & $1.4 \pm 0.09$ \\
\hline 2 & $\begin{array}{l}\text { Gray forest soil with } \\
\text { the introduction of the } \\
\text { phenolic extract }\end{array}$ & $0.4 \pm 0.02$ & $46.5 \pm 0.56$ & $1.1 \pm 0.05$ \\
\hline 3 & $\begin{array}{l}\text { Sand with the addition } \\
\text { of the phenolic extract }\end{array}$ & $0.2 \pm 0.01$ & $32.3 \pm 1.99$ & $0.7 \pm 0.03$ \\
\hline 4 & $\begin{array}{l}\text { Chernozem with clean } \\
\text { water irrigation }\end{array}$ & $0.4 \pm 0.15$ & $59.6 \pm 1.74$ & $1.4 \pm 0.10$ \\
\hline 5 & $\begin{array}{l}\text { Gray forest soil with } \\
\text { clean water irrigation }\end{array}$ & $0.2 \pm 0.02$ & $40.7 \pm 1.52$ & $0.9 \pm 0.06$ \\
\hline 6 & $\begin{array}{l}\text { Sand with clean water } \\
\text { irrigation (control) }\end{array}$ & $0.2 \pm 0.04$ & $22.4 \pm 0.86$ & $0.5 \pm 0.02$ \\
\hline
\end{tabular}

\section{Conclusion}

Different types of soils contain different amounts of the phenolic compounds. With increasing depth of the sampling, the content of the hydroxyaryl compounds decreases. The hydroxyaryl compounds contained in the top soil have a positive effect on the seed germination. The introduction of the polyhydroxyaryl compounds of plant origin activates the intensity of growth processes. This impact can be used for the practical application in various technological operations. In the process of the plant development, the phytostimulating effect of the hydroxyaryl compounds remains at the initial stages; 
therefore, it is especially important to determine the dose of the polyhydroxyaryls used and the mode of plant agrotechnology to preserve and stimulate this effect.

\section{Acknowledgments}

The reported study was funded by RFBR, project number 19-316-90021

\section{References}

1. V.T. Lobkov, S.N. Konoshina,Agricultural biology,39(3),67 (2004)

2. J.C. Streibig, M. Olofsdotter, Journal of Physiologia Plantarum,114(3), 422 (2002)

3. N.A. Olenichenko, E.S. Gorodkova, N.V. Zagoskina, Agricultural biology,43(3), 58 (2008)

4. N.V. Zagoskina, N.A. Olenichenko, C. Yun'vei, E.A. Zhivukhina, Biochemistry and Microbiology,41(1), 99 (2005)

5. E.R. Karimova, E.T. Yamansarova, O.S. Kukovinets, M.I. Abdullin, Bulletin of the Bashkir University,16(4), 1167 (2011)

6. A.M. Grodzinsky, Plant allelopathy and soil fatigue, 460 (1991)

7. M. Olszowy, Plant Physiology and Biochemistry,144, 135 (2019)

8. V. Fogliano, Agric Food Chem Vol,47(3), 1035 (1999)

9. I. Kowalska, L. Pecio, W. Oleszek, A. Stochmal, L. Ciesla Isolation, Journal of Agricultural and Food Chemistry,62(46), 11200 (2014)

10. A.P. Volynets,Hydroxyaryl compounds in the life of plants, 285 (2013) 